\title{
Perspectivas do Banco Mundial para a formação de professores no Brasil: análise crítica
}

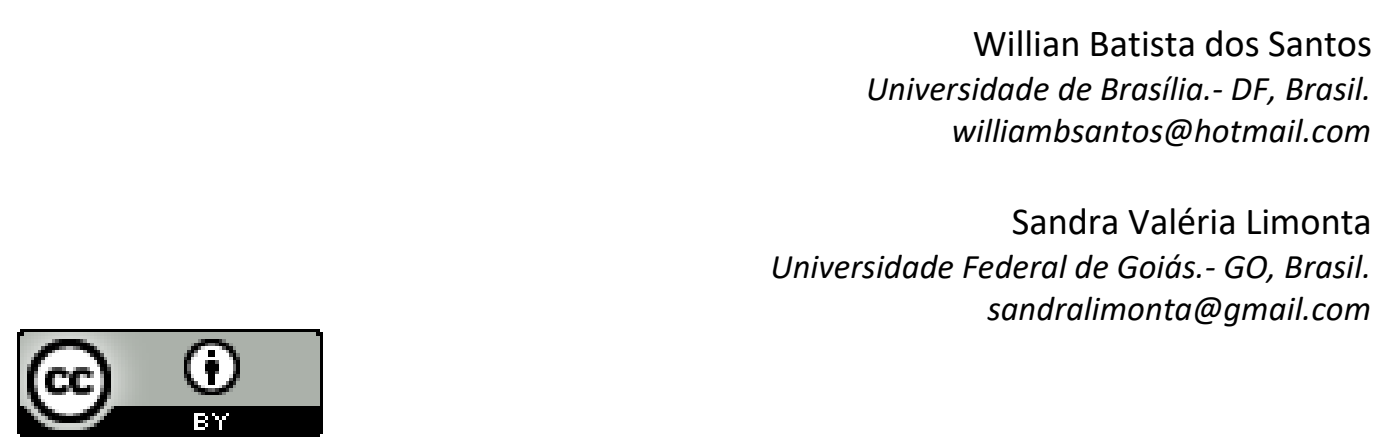

Educação: teoria e prática, Rio Claro, SP, Brasil - elSSN: 1981-8106

Está licenciada sob Licença Creative Common

\section{Resumo}

Este artigo tem como objetivo analisar parte do documento Atingindo uma educação de nível mundial no Brasil: próximos passos, produzido pelo Banco Mundial, no ano de 2010, para orientar a definição de prioridades na política educacional brasileira. Tratase de um recorte de uma pesquisa bibliográfica que analisa as orientações propostas pelo Banco Mundial para a educação dos países em desenvolvimento e como tais orientações têm afetado diretamente as políticas de educação brasileiras. Ao empreender o estudo desse documento em particular, centramo-nos nas ações propostas pelo banco que devem ser adotadas para a melhoria da educação visando à elevação da competitividade econômica do Brasil, principalmente àquelas que dizem respeito ao papel atribuído ao professor nesse processo. Nossas análises revelam que as orientações propostas pelo banco acabaram por se consolidar em programas de formação inicial e continuada estritamente técnicos, sem considerar o já precarizado contexto de trabalho dos professores nas escolas públicas, flexibilizando os conhecimentos teóricos e pedagógicos necessários ao bom ensino e instituindo uma concepção de formação (tanto inicial quanto continuada) que muito se assemelha ao treinamento.

Palavras-chave: Banco Mundial. Políticas de educação. Formação de professors.

\section{Perspectives from the World Bank for teacher education in Brazil: a critical analysis}

\author{
Abstract \\ This article aims to analyze part of the document "Achieving world-class education in \\ Brazil: Next Steps," produced by the World Bank in 2010 to guide the setting of \\ priorities in the Brazilian educational policy. This is a clipping from a literature that
}


analyzes the guidelines proposed by the World Bank for education in developing countries and how these guidelines are directly affecting the educational policy in Brazil. In undertaking the study of this particular document, we focus on the actions proposed by the bank that should be adopted for the improvement of education in order to increase the economic competitiveness of Brazil, especially those that relate to the role assigned to the teacher in this process. Our analyzes reveal that the proposed guidelines by the bank consolidate the initial and continuing training programs strictly technical, without considering the already precarious work environments for teachers in public schools, dispensing the necessary theoretical and pedagogical knowledge and instituting a design for teacher education based only on technical training.

Keywords: World Bank. Educational policies. Teacher education.

\section{Perspectivas del Banco Mundial para la formación de profesores en Brasil: análisis crítico}

\section{Resumen}

Este artículo tiene como objetivo analizar parte del documento Atingindo uma educação de nível mundial no Brasil: próximos passos (Alcanzando una educación de nivel mundial en Brasil: próximos pasos), producido por el Banco Mundial, en el año de 2010, para orientar la definición de prioridades en la política educacional brasileña. Se trata de un recorte de una investigación bibliográfica que analiza las orientaciones propuestas por el Banco Mundial para la educación de los países en desarrollo y cómo tales orientaciones han afectado directamente las políticas de educación brasileñas. Al emprender el estudio de ese documento en particular, nos centramos en las acciones propuestas por el banco que deben adoptarse para la mejoría de la educación con el objetivo de elevar la competitividad económica de Brasil, principalmente aquellas que interesan al papel atribuido al profesor en este proceso. Nuestros análisis revelan que las orientaciones propuestas por el banco acabaron por consolidarse en programas de formación inicial y continuada estrictamente técnicos, sin considerar el ya precarizado contexto de trabajo de los profesores en las escuelas públicas, flexibilizando los conocimientos teóricos y pedagógicos necesarios a la buena enseñanza e instituyendo una concepción de formación (tanto inicial como continuada) que mucho se asemeja al entrenamiento.

Palabras clave: Banco Mundial. Políticas de educación. Formación de profesores.

\section{Introdução}

O estudo empreendido pelo Banco Mundial (BM) em nosso país e publicado em 2010 sob o título Atingindo uma educação de nível mundial no Brasil: próximos passos analisa a trajetória brasileira, nos últimos quinze anos, relacionada à continuidade das políticas e reformas implementadas no campo educacional e também realiza uma 
avaliação comparativa entre o desempenho da educação no Brasil em relação aos membros da Organização para a Cooperação e Desenvolvimento Econômico (OCDE). 0 documento do Banco Mundial aqui analisado foi elaborado com o claro objetivo de orientar as prioridades da política educacional brasileira dos próximos anos.

Qualquer tipo de análise da política educacional brasileira não pode ser realizada fora de uma compreensão do contexto global, pois entendemos que a inserção do país na economia mundial tem se efetivado a partir de sua submissão às regras dos organismos internacionais. Como veremos, as prioridades levantadas no relatório aqui analisado dão seguimento às orientações advindas de uma concepção produtivista de educação que, segundo Saviani (2007), origina-se do ideário neoliberal, visa ajustar a educação escolar às demandas do mercado e à lógica do setor produtivo.

São suficientemente conhecidas as recomendações do Consenso de Washington, que sintetizariam, ao final da década de 1980, as recomendações de organismos como o Fundo Monetário Internacional (FMI) e do BM, entre outros, para que se precise comentá-las. Bastará aqui relacioná-las: equilíbrio orçamentário, sobretudo mediante a redução dos gastos públicos; abertura comercial, pela redução das tarifas de importação e eliminação das barreiras não-tarifárias; liberalização financeira, pela reformulação das normas que restringem o ingresso de capital estrangeiro; desregulamentação dos mercados domésticos, pela eliminação dos instrumentos de intervenção do Estado, como controle de preços, incentivos etc.; e privatização das empresas e dos serviços públicos (SGUISSARDI, 2006, p. 1026).

Dentre as prioridades elencadas no documento do BM (2010), destacamos as ações que devem ser adotadas para a melhoria da educação no que tange à formação de mão de obra qualificada e elevação da competitividade econômica do Brasil no cenário internacional. Buscamos identificar qual é o papel atribuído ao professor, bem como analisar as perspectivas do banco a respeito da formação de professores, uma vez que o documento compreende o docente como elemento fundamental no processo de preparação e qualificação dos futuros trabalhadores.

\section{Educação de nível mundial no Brasil: competitividade, eficiência e produtividade como reguladores da qualidade}

A educação formal, a legislação que a regulamenta e as diretrizes curriculares que a constituem são objetivados para a formação social humana e, por isso mesmo, 
trazem conflitos e contradições a partir do lugar que a educação formal ocupa no modo de produção. Por conseguinte, fazem parte de contextos políticos, sociais, econômicos e culturais próprios da realidade humana, em que a educação é localizada enquanto campo de disputa hegemônica.

Ao analisar a educação hoje, em meio a um mundo que se reestrutura globalmente e que se altera em seu modo de produzir, circular e gerir a vida social mudanças relacionadas às exigências de um mercado em constante expansão, que visa atender aos interesses do capital (MÉSZÁROS, 2007), observamos a construção de projetos bem definidos para o campo educacional, dentre eles, os direcionados à formação humana tanto dos trabalhadores que atuam no campo educacional como do alunado, que serão os trabalhadores de um futuro próximo (FRIGOTTO, 1999).

Diante desse contexto, observamos que não é possível compreender radicalmente a história e a função social da educação na contemporaneidade sem entender o movimento do capital, vinculado às suas ações intencionais voltadas ao gerenciamento das crises capitalistas. Esse processo de regulação das crises tem promovido uma relevante modificação do capitalismo e afetado, de modo determinante, o mundo do trabalho e a educação na segunda metade do século $X X$, mantendo-se em vigor no século XXI (SAVIANI, 2005).

Nesse movimento do sistema capitalista, visando combater as sucessivas crises, verificamos que uma das estratégias tem se baseado no estreitamento das relações entre as bases materiais de produção e os processos educativos, inclusive aqueles desenvolvidos na escola básica. Isso se deve à necessidade do capital em manter o disciplinamento dos trabalhadores frente às modificações implementadas no campo produtivo, bem como prepará-los para acompanhar o desenvolvimento do setor, que se renova constantemente, a partir da década de 1970, passando a se apoiar em bases tecnológicas flexíveis e que demandam o desenvolvimento de novas competências cognitivas complexas. Dentro desse movimento para minimizar as crises, percebemos que ao serem instituídas novas bases materiais para organizar e gerir o campo da produção, consequentemente, passam a ser atribuídas novas responsabilidades e demandas para escola, principalmente no que tange à formação e capacitação de novos trabalhadores (KUENZER, 2005). 
Ao estudarmos as análises e orientações apresentadas no documento produzido pelo BM, vinculadas à formação de mão de obra qualificada e à elevação do nível de competitividade da educação brasileira no cenário internacional, verificamos a ênfase dada à urgência de instrumentalizar os estudantes com as novas habilidades do século XXI fundamentais para formação de um novo perfil de trabalhador, ajustado às novas demandas do setor produtivo.

Os dados do mercado de trabalho no Brasil estão assinalando que as "habilidades do Século 21 " são importantes para a próxima geração de trabalhadores no Brasil, e a produção destes será um desafio crítico para o sistema educacional na próxima década: formandos com a capacidade de pensar analiticamente, fazer perguntas críticas, aprender novas habilidades, e operar com alto nível de habilidades interpessoais e de comunicação, inclusive com o domínio de idiomas estrangeiros e a capacidade de trabalhar eficazmente em equipes. Para o sistema de educação básica, a implicação principal é a da urgência de aumentar a aprendizagem estudantil (BANCO MUNDIAL, 2010).

De acordo com o exposto no documento, a instrumentalização das habilidades do século XXI e a aquisição de competências fundamentais irão proporcionar as mudanças necessárias no perfil dos estudantes, de modo a elevar a qualidade da mão de obra e, consequentemente, aumentar a competitividade da economia brasileira. Mas, advertem que apesar das habilidades da força de trabalho estar melhorando no Brasil, ainda são insuficientes quando comparadas aos países membros da Organização para a Cooperação e Desenvolvimento Econômico (OCDE).

Mesmo tendo o Brasil dado um grande passo na universalização da educação ao reduzir a evasão escolar e aumentar o número de concluintes do Ensino Médio fatores que têm impactado sobre a qualificação da força de trabalho - fica evidente no documento que as taxas de conclusão do ensino médio e a eficiência do fluxo estudantil apresentado pelo Brasil estão bem abaixo dos alcançados pelos países da OCDE. Além disso, os níveis médios de aprendizagem dos alunos brasileiros são considerados inadequados, fator que gera sérias implicações para o aumento da competitividade e crescimento econômico, já que o importante não é o tempo que os estudantes passam na escola e, sim, o que realmente aprendem.

Ao empreendermos uma análise mais profunda a respeito das conclusões e orientações do BM (2010), observamos que diante das modificações nas bases 
materiais de produção, derivadas da transição do taylorismo/fordismo para o toyotismo, notamos exigências na mudança do perfil do trabalhador. Se outrora a relação entre educação e trabalho esteve centrada na formação de um trabalhador especializado, responsável em executar atividades simples, parceladas e repetitivas, com o advento da reestruturação produtiva, passa-se a exigir um novo perfil de trabalhador com novas habilidades cognitivas e comportamentais, mediado pelo conhecimento e por ações flexíveis (KUENZER, 2005; GENTILI, 2005).

Para a efetivação desse processo educativo que visa instrumentalizar os alunos com as novas habilidades no século XXI - para que o país tenha condições de competir no mercado mundial e os trabalhadores possam disputar os poucos postos de emprego que restam - é evidenciado a todo o momento a importância da educação formal e da responsabilidade que se deve assumir perante a formação desse novo perfil de profissional desejado pelo mercado de trabalho.

Gentili (2005), ao analisar o papel atribuído à educação diante das novas exigências do mundo produtivo, aponta que a Teoria do Capital Humano constituiu o principal ajuste teórico usado para definir o sentido da relação trabalho-educação no capitalismo contemporâneo. Essa teoria foi elaborada na Era de Ouro do desenvolvimento capitalista, que foi marcado por uma conjuntura de crescimento econômico, pelo fortalecimento dos Estados de Bem-Estar e pela confiança na conquista do pleno emprego. Dentro desse contexto, a Teoria do Capital Humano desempenhou papel central na certificação e legitimação científica de que a escola e as políticas educacionais podiam e deviam ser um mecanismo de integração dos indivíduos à vida produtiva.

A crise capitalista dos anos 1970 constitui o marco de uma intensa desarticulação da promessa integradora da escola em todos seus sentidos, sendo propagada durante as décadas de 1980 e 1990. Períodos nos quais - mesmo em um cenário de revalorização do papel econômico da educação, propagação de discursos relacionados à importância produtiva dos conhecimentos e ênfase no papel da escola para potencializar a competitividade das economias na era da globalização verificamos uma intensificação no processo de ruptura da promessa da escola como entidade integradora (GENTILI, 2005). 
Esse processo acarretou, não somente, uma modificação nas estratégias políticas direcionadas à certificação da capacidade integradora da educação, como também a uma profunda alteração nos discursos oficiais e nas narrativas acadêmicas que pretendiam legitimar esse objetivo. Neste sentido, a desintegração da educação como promessa integradora não tem como foco negar a relevante contribuição econômica da escolaridade, mas de reafirmar seu novo sentido, vinculado à potencialização das capacidades competitivas do indivíduo para concorrer a uma vaga no mundo da empregabilidade. Assim, perante essa transformação radical de sentido, a escola deixa de ter como responsabilidade a preparação/capacitação dos indivíduos para a aquisição do pleno emprego. Nesse cenário, a educação passa a ser elemento fundamental para manter os indivíduos atualizados e ativos no mundo da empregabilidade.

Assim, podemos afirmar que o termo empregabilidade, fundamentado nos ideais da competitividade e da meritocracia, nasce a partir das novas relações estabelecidas entre capital e trabalho, marcadas pela deslegitimação do Estado, desterritorialização do setor produtivo, desregulamentação e flexibilização de direitos trabalhistas, retração dos postos de trabalho e o aumento exponencial da força de trabalho excedente, com a finalidade de dar novos contornos ao processo de naturalização das desigualdades sociais, ao responsabilizar o trabalhador por seu processo de inclusão/exclusão do mercado de trabalho e da vida social. Dentro desse contexto contraditório e incerto, as exigências vinculadas à formação humana e profissional são potencializadas e, ao trabalhador, passa-se a exigir investimentos em autodesenvolvimento para se adequar às novas e constantes imposições do mercado de trabalho. Diante disso, são construídos discursos vinculados à necessidade de os trabalhadores se atualizarem e adaptarem às novas diretrizes do mundo do trabalho, por meio da absorção de novas competências/habilidades e pela busca incessante de novos conhecimentos.

Saviani (2007) aponta que as exigências oriundas do campo produtivo, relacionadas aos ajustes e readequações pelas quais as novas gerações devem ser submetidas para se ajustar ao mercado de trabalho, constituem um fator essencial para a introdução da pedagogia das competências nas escolas e nas empresas, como 
forma de viabilizar a construção de trabalhadores e cidadãos mais adequados ao tipo de sociedade decorrente da reorganização do sistema produtivo.

Assim, a partir de uma análise do documento, parece que o caminho mais adequado a ser seguido para formar mão de obra qualificada seria aumentar os investimentos na educação básica, de modo a elevar a qualidade do ensino e potencializar a aprendizagem dos alunos. Dentro das prerrogativas apontadas nas orientações do BM, algumas ações como o investimento nas parcerias com o setor privado (que tem apresentado programas e soluções inovadoras) e a continuidade das políticas de avaliação implementadas nos últimos quinze anos (que tem possibilitado a mensuração do aprendizado dos estudantes), são incentivadas.

No entanto, ao estudarmos o documento produzido pelo Banco Mundial (2010), verificamos uma advertência em relação ao aumento dos gastos com educação. Ressalta-se que a elevação dos custos não tem redundado na melhoria da qualidade do ensino e, com base nesse argumento, no documento recomenda-se a redução dos investimentos diretos nesse setor porque: a) no Brasil os gastos com educação são superiores aos empregados pelos países da Organização para a Cooperação e Desenvolvimento Econômico (OCDE); b) com a redução da população brasileira, se a intensidade de investimentos continuarem, futuramente teremos muitos espaços ociosos e professores excedentes; c) o país tem aumentado muito o custo com professores ao reduzir o tamanho médio das salas e promover uma elevação generalizada de seus salários, com poucas evidências de que essas ações contribuem para resultados melhores; d) a repetência no país é elevada e isso constitui uma alternativa ineficaz para aumentar a aprendizagem, além de elevar os gastos; e) a corrupção desenfreada tem promovido uma má aplicação desses recursos, fator que também impede a potencialização do rendimento educacional no país.

Dessa forma, fica evidente que a busca pela elevação da eficiência, da produtividade e da competitividade do sistema educacional deve ser perseguida com a minimização de investimentos financeiros, com o aumento do controle de gastos, ampliação dos mecanismos de fiscalização e melhoria da gestão de recursos, a partir de ações que valorizem os mecanismos de mercado, as parcerias com a iniciativa privada e com o terceiro setor (SAVIANI, 2007). 
Redefine-se, portanto, o papel tanto do Estado como das escolas. Em lugar da uniformização e do rígido controle do processo, como preconizava o velho tecnicismo inspirado no taylorismo-fordismo, flexibiliza-se o processo, como recomenda o toyotismo. Estamos, pois, diante de um neotecnicismo: o controle decisivo desloca-se do processo para os resultados (SAVIANI, 2007, p. 437).

Fica evidente, no documento sob análise, a presença do discurso da área empresarial, subsidiado por conhecimentos do campo da administração que preconizam o gerenciamento eficaz, vinculado à busca de resultados. Por isso, ao lermos as suas entrelinhas, verificamos o constante apelo para se reorganizar o sistema educacional brasileiro à imagem e semelhança da empresa capitalista. Saviani (2007) destaca que o neotecnicismo ganha corpo a partir da busca incessante pela qualidade total na educação ao instituir como objetivos imediatos à satisfação total do cliente e a captura da subjetividade dos trabalhadores. Ambos os elementos são essenciais, mas convencer o trabalhador a vestir a camisa da empresa, ser um colaborador, fazer parte da família exige um denso processo de formação, que deve ser iniciado ainda na escola.

Dentro do projeto capitalista, esse processo de captura da subjetividade do trabalhador não é tarefa a ser executada exclusivamente pelos processos de ensino formal, mas é nesse espaço que valores fundamentais ${ }^{1}$ serão transmitidos para que os alunos se sintam responsabilizados (exclusivamente) pela constituição de sua identidade profissional. Assim, deverão aprender decifrar as exigências do mercado e consumir as habilidades e competências que os possibilitem assumir uma postura empreendedora, proativa, resiliente, mantendo-se automotivados e atualizados com o que há de mais novo, por meio de atitudes que potencializem sua versatilidade, criatividade e polivalência. São por esses motivos que a escola é eleita como peça fundamental dentro do projeto capitalista, responsável por contribuir com a formação desse novo profissional caracterizado pelo seu potencial de adaptabilidade, flexibilidade e assertividade. Para a efetivação desse processo formativo, é necessária a substituição do conhecimento teórico (denso e aprofundado), por um conhecimento

\footnotetext{
${ }^{1}$ Abstração, facilidade de trabalho em equipe, comunicabilidade, resolução de problemas, decisão, criatividade, responsabilidade pessoal sob a produção, conhecimentos gerais e técnico-tecnológicos (língua inglesa e informática, por exemplo), estudar continuamente, entre outras, tornam-se balizadoras do processo educativo para o mundo do trabalho (FRIGOTTO, 1999; KUENZER, 2005).
} 
prático e utilitário, vinculados à construção de habilidades e competências, que visam dar respostas rápidas e eficazes aos problemas que emergem na realidade.

De acordo com Manfredi (2007), as noções de competências previstas como eixo da formação profissional têm sua base teórico-conceitual fundamentada em uma lógica de recomposição da hegemonia do capital, cuja ressignificação da qualificação profissional faz parte de um processo de ressocialização e aculturação da classe trabalhadora, tendo por função reintegrá-la aos novos modelos de produção e gestão do capitalismo, em sua fase de acumulação flexível.

Ao analisar as exigências presentes no documento em análise, vinculada à elevação da competitividade nacional, via formação de mão de obra qualificada, verificamos que o modelo das competências mantém íntima relação com os processos de educação dos trabalhadores ao estabelecer novas configurações de disciplinamento e ao forjar novas subjetividades flexíveis, polivalentes e constantemente educáveis (KUENZER, 2005).

Todavia, para efetivação desse processo, é necessário um sujeito fundamental: o professor. A seguir, buscamos identificar qual é o papel atribuído ao professor, bem como analisar as ações que devem ser implementadas em seu processo formativo para que ele se constitua como um elemento fundamental nesse processo de transformação.

\section{Gerenciando a qualidade dos professores do Brasil}

Pensar a formação inicial e continuada de professores diante do cenário de reestruturação produtiva significa compreender temas de maiores dimensões que exigem uma análise cuidadosa das relações estabelecidas entre o campo econômico, as políticas de cunho neoliberal e os reordenamentos no mundo do trabalho. Tal tarefa é necessária e indispensável, porque é evidente a forma como esses fatores têm incidido e influenciado a composição das políticas educacionais em nosso país.

Nossa análise do documento produzido pelo BM aponta que no cenário mundial há um discurso hegemônico direcionado a naturalizar as relações existentes entre educação, trabalho e desenvolvimento econômico. Dentro desse contexto, cabe aos processos educativos formais promover o desenvolvimento das habilidades da força de trabalho para gerar crescimento econômico, fator que contribuirá com a 
redução da pobreza e da desigualdade através do fornecimento de oportunidades educacionais para todos.

Essa equação nos induz a chegar à simples conclusão: se o país não é competitivo o suficiente para se destacar no cenário mundial, é porque o seu sistema educacional não vai bem. Se o sistema educacional não vai bem, se os alunos não atingem o rendimento esperado e o mercado de trabalho não é provido com profissionais capacitados, a responsabilidade é do professor (EVANGELISTA, 2003).

Dando continuidade ao estudo do documento, verificamos que uma das prioridades apontadas pelo BM, a ser perseguida pelo governo brasileiro, está voltada para a melhoria da qualidade de professores. Esse apontamento é realizado pelo BM, porque a carreira docente no Brasil constitui uma profissão de baixa categoria que não consegue atrair os candidatos de alto rendimento acadêmico. Além disso, assinalam que os professores brasileiros são recrutados do terço inferior dos estudantes do ensino médio.

Dessa forma, o BM adverte que, para o país desenvolver seu potencial competitivo e se adequar aos parâmetros mínimos existentes entre os membros da OCDE, é fundamental que os profissionais da educação passem a ser recrutados do terço superior do Ensino Médio, ou seja, o quadro docente do país não pode mais ser constituído de alunos com baixo índice de aproveitamento acadêmico.

Para a efetivação desse processo de recrutamento de indivíduos com alta capacidade, o governo brasileiro necessitará dar suporte para que os professores melhorem continuamente sua prática de ensino. Além disso, deverão constituir políticas que incentivem a melhoria do desempenho e da produtividade, via programas de incentivo financeiro direcionados a premiar os professores com maior rendimento, instituindo novas diretrizes para a profissionalização docente.

Shiroma e Evangelista (2003), muitos anos antes da publicação aqui analisada, já observavam que a profissionalização do professor foi eleita como agente principal das mudanças a serem instituídas para melhorar a qualidade do ensino e do desenvolvimento econômico do país. Nesse sentido, faz-se necessário "profissionalizar o docente reconstruindo suas práticas sem perder de vista as relações entre trabalho e seu objetivo educativo" (SHIROMA; EVANGELISTA, 2003, p. 88). 
As autoras também advertem que esse projeto de formação docente, assim como em outros momentos históricos, foi constituído com o objetivo de recompor e assegurar a hegemonia dominante, já que o professor constitui um recurso humano de elevada importância e, por isso, deve ser (con)formado sobre novas bases, de modo a contribuir na produção de uma nova forma de perceber e estar no mundo, adequada aos interesses do capital (SHIROMA; EVANGELISTA, 2003). Entretanto, Kuenzer e Caldas (2009, p. 24) advertem que há uma peculiaridade no trabalho docente pois,

(...) a contribuição para o processo de acumulação se dá com base em uma característica muito peculiar do trabalho: a sua natureza não material, já que não é possível separar o produtor de seu produto. Essa natureza limita, de certo modo, a realização do trabalho segundo o modo capitalista, que passa a se dar indiretamente, por meio de diferentes mediações que "convençam" o trabalhador, pela força ou pela persuasão, a ser artífice da própria exploração, ao mesmo tempo que busca sua realização pessoal, vinculada a finalidades. Ou seja, no trabalho não material, a subsunção do trabalho ao capital apresenta limites, com o que se ampliam as possibilidades de resistência e de autonomia; nesse caso, a subsunção depende mais fortemente da adesão do trabalhador.

Apesar da natureza não material do trabalho docente constituir uma possibilidade para a construção de projetos de resistência às cobranças e exigências derivadas do modo capitalista de produção, observamos que os professores vêm sendo convencidos através da força a serem autores da própria exploração.

Afirmamos isso porque junto com as novas exigências e responsabilidades atribuídas ao professor, verificamos a intensificação dos processos de precarização do trabalho docente, marcados:

1. Pela redução do tempo livre (ao terem que trabalhar em diferentes unidades de ensino, fator que aumenta suas jornadas laborais e, que em vários casos, são estendidas para fora do que é tolerado pela Legislação Trabalhista em vigor).

2. Aumento dos vínculos empregatícios parciais, temporários, terceirizados, comissionados, etc. (que ao serem muito cobrados em sua produtividade e sem contar com o maior amparo legal, amargam com a instabilidade e a insegurança).

3. Falta de recursos técnicos, humanos e financeiros para as unidades de ensino. 
4. Afastamento do trabalho, devido aos problemas crônicos de saúde (síndrome de Burnout, síndrome do pânico, estresse, problemas cardiovasculares, alcoolismo, tabagismo, câncer de pele, etc.) (GASPARINI et al, 2005; CODO E MENESES, 2006).

5. Aumento do assédio moral, do preconceito e da violência contra os professores.

6. Ausência de programas públicos de formação continuada de professores (dentro e fora do espaço de trabalho), situando a responsabilidade de continuidade da formação no próprio docente.

7. Achatamento salarial decorrente do enxugamento de gastos pelo Estado.

8. Perda ou deslegitimação de direitos sociais (como alterações no plano de carreira dos servidores do magistério para atender os interesses do Estado e do capital).

9. Cobrança do aumento da produtividade e dos níveis de exigência institucionais (traduzidos pelo termo meritocracia), tanto para os docentes temporários como para os estáveis/concursados.

Somado aos processos de precarização das condições de trabalho do professor, identificamos novos projetos vinculados ao barateamento, flexibilização e aligeiramento da formação docente, que também forçam os professores a adequarem suas ações às diretrizes estabelecidas pelo modelo capitalista. Esses novos projetos são guiados por ações que visam: a) relegar a teoria para segundo plano; b) priorizar um novo tipo de conhecimento profissional baseado na aquisição de habilidades práticas; c) priorizar o desenvolvimento de pesquisas vinculadas à realidade e à prática educacional; d) promover ações voltadas a diminuir o custo do professor (estagnação de reajustes salariais e melhorias nas condições de trabalho), via aumento da produtividade (meritocracia); e) instituir mecanismos de controle sobre o trabalho docente (SHIROMA; EVANGELISTA, 2003; MORAES; TORRIGLIA, 2003; FREITAS, 2007).

Quando analisamos as ações propostas no documento sob análise, fica evidente que o argumento da competência/incompetência profissional visa substituir os objetivos formativos nos cursos de formação inicial e continuada por competências a serem desenvolvidas via instrumentalização de habilidades específicas, subsidiadas 
por técnicas direcionadas à resolução dos problemas cotidianos, visando maximizar a atuação do professor em sala de aula.

Essas ações fazem parte de um movimento, em nível internacional, de proletarização, desintelectualização e controle do trabalho do professor, que visa modelar um novo perfil de profissionalismo docente, caracterizado pela elevada competência técnica e mínima consciência política (SHIROMA, 2003).

Em vez de cursos teóricos, os programas de formação profissional projetados a partir das evidências das observações em sala de aula usam vídeos e exercícios práticos para ensinar técnicas eficazes de uso do tempo na sala de aula, do uso de materiais de aprendizagem e para manter os estudantes ocupados na tarefa. Este treinamento voltado para a prática é a nova direção na qual os países da OCDE estão partindo, e os estados mencionados anteriormente (Pernambuco e Minas Gerais) e o município do Rio de Janeiro estão na vanguarda (BANCO MUNDIAL, 2010, p. 6).

Fica evidente nesse excerto que a principal estratégia para aumentar a eficiência do processo de ensino e aprendizagem é treinar o professor por intermédio de técnicas eficazes e de exercícios práticos, que os possibilitem maximizar o aproveitamento dos alunos em sala de aula. Nesse processo deve-se privilegiar o conhecimento prático em detrimento do conhecimento teórico, que se mostra ineficiente e inadequado ao novo modelo de formação a ser alcançado.

Moraes (2003) destaca que, perante esse movimento de celebração do fim da teoria, parte constituinte de uma nova utopia praticista, o conhecimento teórico não passa de uma especulação metafísica. Nesse contexto, a produção do conhecimento deve ser regulada pelo know-how que produz, ou seja, pela construção de respostas almejadas pelo setor produtivo e pelo mercado. Isso significa dizer que a produção do conhecimento deve ser direcionada para a fabricação de resultados concretos e imediatos, mesmo que seja marcada por uma prática desprovida de reflexão. Tal fator tem contribuído diretamente para a ressignificação do papel do professor, da formação acadêmica, da produção do conhecimento e da pesquisa científica.

Esse processo de descaracterização, desqualificação e vulgarização da teoria e da pesquisa científica no campo educacional aposta na falência de uma determinada concepção de razão (MORAES, 2003), na supervalorização da experiência imediata (MORAES; TORRIGLIA, 2003), na legitimação do desempenho via instrumentalização de competências e habilidades, voltadas às necessidades do campo produtivo. 
Além disso, o apelo para as técnicas eficientes de ensino, a utilização de materiais adequados à aprendizagem, o controle rígido do tempo, a partir de um treinamento estreitamente ligado à prática, faz parte do novo pacote estratégico para controlar o trabalho docente.

Em Minas Gerais, Pernambuco e no município do Rio de Janeiro, dados mostram que enquanto a norma da OCDE para cada hora de instrução usada eficazmente com atividades de aprendizagem é de 85 por cento, nenhum dos sistemas brasileiros estudados passa de 66 por cento. Conforme está detalhado no capítulo, os professores brasileiros usam uma proporção substancial do tempo em sala de aula praticando atividades rotineiras como fazendo a chamada e recolhendo deveres de casa. Uma alta proporção de professores também não faz uso dos materiais de aprendizagem disponíveis, e de 43-64 por cento do tempo os estudantes estão visivelmente desocupados (em países da OCDE, o ponto de referência para estudantes desocupados é de 6 por cento ou menos do tempo) (...) Com o apoio da equipe de educação do Banco Mundial, esses sistemas escolares também estão usando métodos padronizados de observação em sala de aula desenvolvidos nos países da OCDE para olhar dentro da "caixa-preta" da sala de aula e identificar quais são os exemplos de boas práticas de professores que podem ancorar os seus programas de desenvolvimento profissional (grifos nosso) (BANCO MUNDIAL, 2010, p. 6).

Os pacotes estratégicos, responsáveis em reestruturar o trabalho docente, são uma das formas eleitas para controlar o trabalho do professor. Como podemos observar no trecho acima, as orientações em curso retiraram do professor a pouca autonomia que lhe restava, ao invadir seu espaço de trabalho para avaliar sua conduta profissional.

O olhar que direcionam para dentro da sala de aula, ou melhor, para dentro da caixa preta $^{2}$ - a partir de seus métodos padronizados de observação, guiados por critérios advindos do campo da economia e administração -, visa extrair dados que atestem a incompetência dos professores e validem intervenções sistemáticas sobre seu trabalho, bem como ações direcionadas a baixar custos, redefinir gastos e centralizar o controle sobre as políticas implementadas, de modo a garantir sua produtividade, eficácia, excelência e eficiência.

Em síntese, o documento, ao apresentar as prioridades para melhorar a qualidade dos professores no Brasil, assevera que, para formar o novo trabalhador polivalente, flexível e adequado às novas exigências do mundo produtivo, é necessário

\footnotetext{
${ }^{2}$ A caixa-preta é um dispositivo utilizado em aeronaves para gravar as informações essenciais sobre o avião e o voo. Esse instrumento tem a finalidade de registrar todas os diálogos e ações estabelecidas entre os tripulantes da cabine, além de dados importantes como: velocidade, aceleração, altitude e ajustes de potência, entre outros.
} 
abandonar o velho professor e fazer ressurgir em seu lugar um novo profissional da educação, um novo professor competente, multitarefa, flexível, acrítico e apolítico.

\section{Considerações finais}

Melhorar a qualidade da formação e do trabalho dos professores do Brasil é uma prioridade e disso não temos dúvida nem discordâncias. Contudo, é importante refletirmos sobre algumas questões: Melhorar a qualidade dos professores do Brasil para atender a que interesses? O que é necessário para aprimorar o trabalho docente? É possível aperfeiçoar e maximizar o trabalho docente, a partir da negação do conhecimento teórico em detrimento de um conhecimento prático?

Como podemos identificar ao longo dessa pesquisa, o Banco Mundial estabeleceu uma agenda de prioridades que devem ser efetivadas pelo governo brasileiro. As metas estipuladas, consoantes com o ideário neoliberal, preveem a racionalização do campo educativo, que deve acompanhar a lógica do campo econômico, sobretudo, a partir da adoção de programas de ajuste estrutural, voltados à profissionalização docente, visando desenvolver as habilidades da força de trabalho para gerar crescimento econômico sustentável, fator que contribuirá com a redução da pobreza e da desigualdade através do fornecimento de oportunidades educacionais para todos.

Dentro desse cenário, no qual o professor é eleito como peça fundamental na transmissão de valores essenciais para formação de um novo perfil de trabalhador, identificamos as recomendações do BM direcionadas à racionalização e controle do trabalho docente, via recomendação de pacotes estratégicos, cuja premissa é dar mais versatilidade as suas ações, para responder com eficácia às diversas necessidades externas, em particular do setor produtivo e do mercado, tendo como foco a qualidade total no ensino, a gestão gerencial e a racionalidade técnica, instituída a partir de uma forma de capacitação profissional fragmentada, pragmática, instrumentalista e utilitarista, intimamente vinculada à noção de competências.

Além disso, observamos que as orientações apresentadas pelo BM têm sua base teórico-conceitual fundamentada em uma lógica de recomposição da hegemonia do capital, em que a ressignificação da qualificação profissional faz parte de um 
processo de ressocialização e aculturação da classe trabalhadora, tendo por função reintegrá-la aos novos modelos de produção e gestão do capitalismo.

Assim, a suposta melhoria da qualidade dos professores, proposta pelo BM, tem como finalidade capacitar os futuros docentes para atender às novas exigências do campo produtivo, relacionadas ao desenvolvimento de habilidades cognitivas e comportamentais, bem como a instrumentalização de valores e habilidades exigidas pelas novas e crescentes demandas do mercado, legitimadas pelos princípios do mérito individual, da competitividade, da flexibilidade, todavia, ainda submetidos ao jugo da exploração humana e de formas de trabalho cada vez mais desqualificadas, intensificadas e precarizadas.

Diante disso, acreditamos que a formação inicial e continuada de professores não podem ser reduzidas a um saber-fazer que não contribui para que os docentes rompam com uma visão imediatista, pragmática e unilateral da realidade. Por isso, aliamo-nos aos diversos pesquisadores que demarcam seus estudos a partir do materialismo histórico-dialético, para defender uma perspectiva de formação humana e profissional balizada por um processo de enriquecimento pessoal, intelectual, técnico e político-social, que, ao possuir sua origem no trabalho, visa proporcionar a apropriação de ferramentas intelectuais altamente desenvolvidas que contribuam com o processo formativo dos professores, auxiliando-os a desvelar as contradições presentes no modelo capitalista, bem como formar novas atitudes perante a escola, a sociedade, a vida.

\section{Referências}

BANCO MUNDIAL. Atingindo uma educação de nível mundial no Brasil: próximos passos. Sumário executivo, 2010.2 Disponível em: http://www.todospelaeducacao.org.br/biblioteca/1390/atingindo-uma-educacao-denivel-mundial-no-brasil-proximos-passos---sumario-executivo/ Acesso em: 10 mai. 2013.

CODO, W.; MENESES, I. V. O que é burnout? In: (Org.). Educação: carinho e trabalho. 4 ed. Petrópolis: Vozes, 2006. p.237-254. 
FREITAS, H. C. L. de. A (nova) política de formação de professores: a prioridade postergada. Educação e Sociedade, Campinas, v. 28, n. 100 - Especial, p. 1203-1230, out. 2007.

FRIGOTTO, G. Educação e crise do capitalismo real. 3 ed. São Paulo: Cortez, 1999.

GENTILI, P. Três teses sobre a relação trabalho e educação em tempos neoliberais. In: LOMBARDI, J. C.; SAVIANI, D.; SANFELICE, J. L. (Orgs.). Capitalismo, trabalho e educação. 3 ed. Campinas: Autores Associados/HISTEDBR, 2005. p. 45-59.

KUENZER, A. Z. Exclusão includente e inclusão excludente: a nova forma de dualidade estrutural que objetiva as novas relações entre educação e trabalho. In: SAVIANI, D.; LOMBARDI, J. C.; SAFELICE, J. L. (Orgs.). Capitalismo, trabalho e educação. 3 ed. Campinas: Autores Associados/HISTEDBR, 2005. P.77-96.

KUENZER, A. Z.; CALDAS, A. Trabalho docente: comprometimento e desistência. In: FIDALGO, F.; OLIVEIRA, M. A. M.; FIDALGO, N. L. R. (Orgs.). Intensificação do trabalho docente: tecnologias e produtividade. Campinas: Papirus, 2009. P. 19-48.

MANFREDI, S. M. Qualificação e educação: reconstruindo nexos e inter-relações. In: SAUL, A. M; FREITAS, J. C. (Orgs). Políticas Públicas de qualificação: desafios atuais. São Paulo: A+ Comunicação, 2007. p.11-36.

MÉSZÁROS, I. A educação para além do capital. São Paulo: Boitempo, 2007.

MORAES, M. C. M. de. O recuo da teoria. In: . (Org.). lluminismo às avessas: produção de conhecimento e políticas de formação docente. Rio de Janeiro: DP\&A, 2003. P. 151-167.

MORAES, M. C. M. de; TORRIGLIA, P. L. Sentidos de ser docente e da construção de seu conhecimento. In: - (Org.). Iluminismo às avessas: produção de conhecimento e políticas de formação docente. Rio de Janeiro: DP\&A, 2003. p. 45-60.

SAVIANI, D. Transformações do capitalismo, do mundo do trabalho e da educação. In: LOMBARDI, J. C.; SAVIANI, D.; SANFELICE, J. L. (Orgs.). Capitalismo, trabalho e educação. 3 ed. Campinas: Autores Associados/HISTEDBR, 2005. P. 13-24. 
SAVIANI, D. História das ideias pedagógicas no Brasil. Campinas: Autores Associados, 2007.

SGUISSARDI, V. Reforma universitária no Brasil - 1995-2006: precária trajetória e incerto futuro. Educação e Sociedade, Campinas, v. 27, n.96 - Especial, p. 1021-1056, out. 2006.

SHIROMA, E. O. O eufemismo da profissionalização. In. MORAES, M. C. M. (Org.). Iluminismo às avessas: produção de conhecimento e políticas de formação docente. Rio de Janeiro: DP\&A, 2003. P. 61-79.

SHIROMA, E. O.; EVANGELISTA, O. Um fantasma ronda o professor: a mística da competência. In. MORAES, M. C. M. de (Org.). Iluminismo às avessas: produção de conhecimento e políticas de formação docente. Rio de Janeiro: DP\&A, 2003. P. 81-

Enviado em Abril/2014

Aprovado em Agosto/2014 